\title{
Comunicação e movimentos sociais contemporâneos: um panorama analítico a partir das categorias da totalidade e da contradição ${ }^{1}$
}

Leila Salim LEAL ${ }^{2}$

\begin{abstract}
Resumo:
O artigo apresenta um panorama contemporâneo sobre as relações entre movimentos sociais e comunicação adotando como recorte a crise capitalista iniciada ao final da primeira década do século XXI. No contexto da emergência de mobilizações sociais de grande porte, o papel mobilizador e aglutinador das novas tecnologias de comunicação e a constituição de redes de comunicação alternativas, próprias dos movimentos, vêm sendo apontados como marcas constitutivas fundamentais desse processo de mobilização global. Parece-nos necessária a elaboração de uma reflexão que seja capaz de problematizar o papel e o sentido da comunicação para a constituição desses movimentos, levando em consideração não apenas a utilização das tecnologias digitais como instrumento mobilizador, mas também buscando compreender que questões, referentes à natureza e inserção desses movimentos no capitalismo contemporâneo, podem ser reveladas a partir da identificação da importância assumida pela comunicação e pela cultura em sua constituição.
\end{abstract}

Palavras-chave: Comunicação. Cultura. Movimentos sociais. Crise econômica. Consciência.

\section{Communication and contemporary social movements: an analycal panorama from the categories of totality and contradiction}

\begin{abstract}
:
This article presents a contemporary overview of the relations between social movements and communication. It's starting point is the capitalist crisis that began at the end of the first decade of the 21 st century. In the context of the emergence of large social mobilizations, the mobilizing and agglutinating role of new communication technologies and the constitution of alternative communication networks have been pointed out as fundamental constitutive marks of this process. It is necessary to elaborate a reflection that could problematizing the role and meaning of communication for the constitution of these movements, taking into consideration not only the use of digital technologies as a mobilizing instrument, but also seeking to understand what issues, referring to the nature and insertion of these movements in contemporary capitalism can be revealed by identifying the importance assumed by communication and culture in its constitution.
\end{abstract}

Keywords: Communication. Culture. Social movements. Economic crisis. Consciousness.

\footnotetext{
${ }^{1}$ Artigo resultante da apresentação feita pela autora na mesa Comunicação e movimentos Sociais, panorama histórico contemporâneo, do XII Encontro Nacional de História da Mídia/Alcar 2019, realizado em Natal/RN. A apresentação foi elaborada a partir da tese de doutorado Culpe a era em que vivemos: comunicação, cultura e sujeito nos movimentos sociais contemporâneos, defendida pela autora em 2017 no Programa de Pós-Graduação em Comunicação e Cultura da Universidade Federal do Rio de Janeiro (PPGCOM/UFRJ).

${ }^{2}$ Jornalista e Doutora em Comunicação e Cultura pela UFRJ, professora substituta do Departamento de Comunicação da Universidade Federal do Rio Grande do Norte (Decom/UFRN). E-mail: leilasalimleal@yahoo.com.br.
} 


\section{Comunicación y movimientos sociales contemporáneos: un panorama analítico desde las categorías de totalidad y contradicción}

Resumen:

El artículo presenta una visión general contemporánea de las relaciones entre los movimientos sociales y la comunicación. Tiene como recorte temporal la crisis capitalista que empezó a fines de la primera década del siglo XXI. En el contexto del surgimiento de grandes movilizaciones sociales, el papel de las nuevas tecnologías de comunicación y la constitución de redes de comunicación alternativas se han señalado como marcas constitutivas fundamentales de este proceso de movilización global. Nos parece necesario elaborar una reflexión que sea capaz de problematizar el papel y el significado de la comunicación para la constitución de estos movimientos, teniendo en cuenta no solo el uso de las tecnologías digitales como instrumento de movilización, sino también buscando comprender qué temas referentes a la naturaleza e inserción de estos movimientos en el capitalismo contemporáneo puede revelarse identificando la importancia asumida por la comunicación y la cultura en su constitución.

Palabras clave: Comunicación. Cultura. Movimientos sociales. Crisis económica. Conciencia.

\section{Introdução: um recorte, uma abordagem}

O panorama contemporâneo sobre as relações entre movimentos sociais e comunicação que pretendemos desenvolver parte de um recorte: a partir de 2011, o debate acerca das formas de organização coletiva e transformação social na contemporaneidade ganhou novo ânimo. No contexto da crise capitalista iniciada ao final da primeira década do século XXI, a emergência de mobilizações sociais de grande porte - das quais foram

expoentes o enfrentamento e derrubada de ditaduras na região norte da África, as lutas contra a retirada de direitos sociais na Europa e o questionamento à ordem econômica, política e social imposta por grandes bancos e empresas transnacionais nos Estados Unidos (EUA) - estremeceu as bases do consenso estabelecido e assumiu ares de movimentação global, epidêmica, mesmo diante das importantes diferenças entre as situações específicas e reivindicações imediatas sobre as quais se desenvolvia nas diferentes regiões.

A mobilização na Praça Tahrir, no Egito, serviu de exemplo para os movimentos da Espanha, Grécia, Portugal e Estados Unidos, transformando a ocupação de praças em um método comum e, até mesmo, constitutivo de uma identificação compartilhada pelos movimentos ao redor do mundo. Foram ocupadas a Praça Puerta Del Sol, em Madrid; a Praça Syntagma, em Atenas; e o Zuccotti Park, no coração financeiro de Nova Iorque. A chamada "Primavera Árabe", dessa e de outras formas, associou-se ao Movimento dos Indignados espanhóis, à Geração à Rasca de Portugal e ao Movimento Occupy, que se apresentou com esta denominação inicialmente no movimento de Wall Street, mas rapidamente se espalhou para outras regiões dos EUA (JINKINGS, 2012). 
Mas, se em 2011 a conjuntura brasileira ainda não havia sido definitivamente atravessada pelos novos ares rebeldes do mundo, em 2013 junho trouxe ao Brasil a maior mobilização de massas de sua história. As manifestações iniciadas pelo Movimento Passe Livre, especialmente em São Paulo, desembocaram em protestos nacionais que aconteceram em mais de quinhentas cidades, envolvendo milhões de pessoas. Tão expressivos quanto difusos politicamente e profundamente afetados pelos agendamentos operados pelos meios de comunicação hegemônicos, que se colocaram na disputa de seus rumos e pautas, os protestos identificados como "Jornadas de Junho" têm sido temas de intensas polêmicas, debates e, de uma maneira ou de outra, provocaram inflexões profundas que seguem afetando o cenário político nacional.

Nesse contexto, o papel mobilizador e aglutinador das novas tecnologias de comunicação, especialmente a partir das redes sociais na internet, e a constituição de redes de comunicação alternativas, próprias dos movimentos, vêm sendo apontados, por diversos analistas e em vários sentidos, como marcas constitutivas fundamentais desse processo de mobilização global. Parece-nos definitiva a elaboração de uma reflexão que seja capaz de problematizar o papel e o sentido da comunicação para a constituição desses movimentos, levando em consideração não apenas a utilização das tecnologias digitais como instrumento mobilizador e os veículos e peças de comunicação por eles produzidos, mas também buscando compreender que questões, referentes à natureza e inserção desses movimentos no capitalismo contemporâneo, podem ser reveladas a partir da identificação da importância assumida pela comunicação e pela cultura em sua constituição.

Daí deriva a necessidade de uma reflexão mais ampla sobre o lugar dos meios de comunicação na sociabilidade capitalista contemporânea e seu papel como instrumento de mediação nos processos de formação da consciência dos indivíduos na contemporaneidade, profundamente atravessados pela ideologia e pela reificação. Em grande medida, a centralidade assumida pela comunicação na constituição dos movimentos sociais deriva da verificação da necessidade, pelos próprios movimentos, de elaboração autônoma de seus discursos em contraposição ao tratamento fragmentado, descontextualizado, criminalizatório ou superficial elaborado pelos meios hegemônicos.

Defendemos que a investigação sobre o sentido da comunicação nos movimentos sociais contemporâneos precisa, a partir da categoria da totalidade, ser capaz de identificar o que há de novo e/ou específico na relação entre o capitalismo contemporâneo e a mídia, discutindo o lugar ocupado pelos meios de comunicação na reprodução ideológica e material do capitalismo, o tipo de sociabilidade que expressam e produzem 
e como agendam a disputa política especificamente, colocando no centro do debate as conexões entre a cultura da mídia e o status da reificação, da alienação e da ideologia sob as condições impostas pelo capitalismo contemporâneo.

Se, como apontamos, direta ou indiretamente a produção de comunicação autônoma pelos movimentos se relaciona à identificação de sua centralidade para a disputa da consciência e dos rumos da política na sociedade contemporânea, e se, como também assinalamos, a comunicação é parte definitivamente constitutiva - e destacada dos movimentos da reificação e da alienação no capitalismo contemporâneo, parece-nos central perceber em que medida a comunicação própria dos movimentos, ao se desenvolver no campo de uma práxis contestatória e/ou antissistêmica, resiste e refuta, mas também importa e reproduz, as marcas ideológicas e reificadas da comunicação hegemônica.

Parte de nosso esforço analítico, portanto, se concentra em uma investigação sobre as especificidades do capitalismo contemporâneo e sua atual fase de reprodutibilidade neoliberal, notadamente sobre as conexões entre o atual estágio do capitalismo neoliberal e o campo da cultura. As principais características do funcionamento da economia neoliberal nos demonstram que, ao contrário do que difunde o senso comum, o neoliberalismo não significa a ausência ou desaparecimento do Estado. Pelo contrário, a falta de regulamentação do fluxo de capitais e a apropriação privada da atividade econômica significam uma intervenção estatal que tem como objetivo garantir a subordinação do público ao privado. Trata-se, portanto, de uma forma de regulação não declarada do Estado.

Dessa forma, esse mecanismo de intervenção não declarada do Estado na economia representando interesses privados também se manifesta no âmbito do discurso, no que se refere às relações ideológico-simbólicas que influenciam os processos de produção, circulação e consumo de mercadorias. No neoliberalismo, o desenvolvimento sem precedentes da indústria cultural a partir do deslocamento do investimento de capitais para o setor de serviços faz com que o papel ideológico desempenhado pelos veículos de comunicação para a reprodução do capitalismo dê um salto de qualidade (JAMESON, 2002).

A televisão, jornais, revistas, a web e a indústria do entretenimento, desempenhando papel de relevância cada vez maior na sociedade, são utilizados para imposição do discurso mercantil hegemônico no neoliberalismo. A perspectiva de "autonomia" do mercado "autorregulável" legitima não apenas as políticas econômicas 
adotadas pelo Estado, mas também engendra uma sociabilidade profundamente atravessada por uma perspectiva de fugacidade, fragmentação e individualismo que concebe as formas de realização humana como isoladas e "projetos de sucesso" análogos aos desenvolvidos por corporações no mercado capitalista. A partir desta identificação, buscamos investigar o neoliberalismo também como ideologia no capitalismo contemporâneo e suas expressões culturais e políticas, sobretudo àquelas vinculadas aos movimentos sociais (JAMESON, 2002).

Algumas análises têm apontado, de maneira geral, que os chamados "novos movimentos sociais" surgidos em 2011 são uma necessária expressão da pósmodernidade e suas identidades mediadas pela cultura e pelo discurso (CASTELLS, 2013). Interessa-nos, aqui, refletir mais profundamente sobre esse tema, levando em consideração a hipótese de que tais movimentos possam indicar sinais de volta à cena dos grandes processos de transformação social protagonizados por sujeitos coletivos, que encontrem na comunicação e na cultura formas de reconstituição de algo tido como ultrapassado. Questionamos a ideia de que o papel desempenhado pela comunicação e pela cultura nos "novos movimentos sociais" significa necessariamente a superação definitiva das lutas de cunho econômico e estrutural, buscando identificar que formas de associação entre essas esferas podem ser expressadas por esses processos políticos.

\section{Crise capitalista e a explosão dos movimentos sociais a partir de 2011}

Sob o cenário da atual crise econômica, apontada como a maior desde 1929, emergem os movimentos sociais que marcaram o ano de 2011. Parece-nos fundamental associar o surgimento desses movimentos ao contexto colocado pela crise do capitalismo. Especialmente diante de análises (CASTELLS, 2013) que compreendem o papel da comunicação e da cultura nesses movimentos como índices da constituição de identidades fluidas, discursivas e cada vez menos relacionadas às estruturas objetivas do capitalismo contemporâneo, é indispensável que nos questionemos sobre os motivos de tais movimentos eclodirem neste momento específico, com tanta força e caráter "epidêmico". O eixo comum de tais chaves analíticas é justamente a compreensão dos "novos movimentos sociais" a partir do descolamento das determinações materiais e econômicas, buscando situá-los unicamente como movimentos circunscritos aos campos da subjetividade, do discurso e da cultura.

Ao mesmo tempo, é também fundamental que, ao buscar as razões comuns e identificar o "chão material" da emergência de tais processos contestatórios, tenhamos 
atenção às suas formas específicas de constituição em cada formação social, inclusive percebendo os fatores locais que concorreram para sua eclosão, evitando assim que a identificação da crise do capital se torne uma explicação genérica e simplista para tais processos

Aqui nos interessa, fundamentalmente, destacar que o conjunto da resposta que o capitalismo elaborou à sua crise estrutural atinge diretamente a classe trabalhadora e a juventude em suas condições de vida mais imediatas e segue apontando para a busca de manutenção da lógica de valorização do capital fictício à custa da piora da condição de vida da classe trabalhadora (CARCANHOLO, 2011). Obviamente, o fato de ser a classe trabalhadora a principal afetada pelos "ajustes" capitalistas em sua crise não garante historicamente uma resposta sua, como classe, a essa ofensiva. E também, certamente, não significa que a classe como tal seja a principal expressão imediata e espontânea da resistência e enfrentamento a esse processo.

No entanto, identificar a classe trabalhadora como o principal sujeito anticapitalista nos permite exatamente notar a sua inserção objetiva nas formas de produção e reprodução do sistema, o que a capacita para, ao levar suas lutas adiante, enfrentar o cerne das contradições do modo de sociabilidade vigente. Essa inserção objetiva é, portanto, decisiva, mas não exclusiva para a constituição de uma resposta que possa enfrentá-lo como totalidade. Para isso, a categoria da política, com todas as suas mediações, é indispensável. É justamente por isso que nossa análise busca estabelecer nexos entre a eclosão dos movimentos sociais contemporâneos e a crise estrutural capitalista, indicando tais movimentos não como uma expressão acabada, mas como possíveis sinais de uma retomada da classe trabalhadora como sujeito político no momento de desagregação capitalista.

Seguindo o esforço de compreender tais movimentos em suas especificidades e relações com o capitalismo contemporâneo - de onde deriva o tema da comunicação, da cultura e seus papéis na constituição do sujeito -, apontamos a importância de uma análise desses movimentos sociais a partir de uma perspectiva que leve em consideração a noção de totalidade. Essa perspectiva pode compreender a eclosão e desenvolvimento desse processo não como uma negação, mas sim como um momento da reconstituição, sobre as novas bases colocadas pelas modificações na estrutura do capitalismo, na noção de sujeito e dos projetos totalizantes.

Não há dúvidas do caráter exemplar que a ocupação da Praça Tahrir, no Egito, desempenhou para as mobilizações na Espanha, Grécia e Portugal, e destas para as 
manifestações nos EUA. As ocupações das praças Puerta Del Sol, em Madrid, Syntagma, em Atenas, e do Zuccotti Park, no coração financeiro de Nova Iorque, faziam referências diretas e indiretas à Tahrir e à luta do povo egípcio. Cartazes dos indignados afirmavam textualmente, referindo-se à Puerta Del Sol: "Aqui é a nossa Praça Tahrir" (THOUSANDS..., [S.d.], não paginado). Nos EUA, o Movimento Occupy se desenvolve inicialmente em Wall Street, mas ganha fôlego em outras regiões do país e do mundo.

Da mesma forma, é esse contex to que marca e impulsiona, de nosso ponto de vista, as mobilizações ocorridas no Brasil em 2013, marcadas pelo encerramento de um ciclo ascendente na economia que propiciou um inclusão das camadas populares, sobretudo por meio do consumo e políticas sociais focalizadas, acompanhado da piora das condições de vida nos grandes centros urbanos, da restrição de direitos e do contraste evidenciado entre este cenário e os grandes investimentos públicos nos megaeventos esportivos realizados no país no mesmo período.

Se há, e isso está claro, diferenças específicas entre o conteúdo das mobilizações, as reivindicações centrais, os setores que as protagonizam, além dos grandes abismos entre as formações sociais e os regimes vigentes nesses países, há, também, aproximações significativas, e o que pretendemos demonstrar aqui é que tais convergências não se resumem apenas - ou isoladamente - ao campo estético e subjetivo. Em nosso esforço, buscamos compreender tal identidade subjetiva (que se manifesta claramente em exemplos como o citado acima, seja na utilização de métodos de mobilização semelhantes, na característica comum que é a utilização de recursos estéticos, visuais, cênicos, musicais e audiovisuais nos processos de luta, seja no próprio conteúdo expresso nesses recursos estéticos) como índice de um processo global marcado por um mesmo determinante objetivo.

\section{Movimentos socias, comunicação e cultura}

Estamos tratando de movimentos caracterizados, de maneira geral, por uma ruptura com a reprodução acrítica e cotidiana da ordem estabelecida, ao mesmo tempo em que mantêm suas críticas e práticas na ordem dos elementos palpáveis na vivência cotidiana. Em função de sua natureza espontânea, escapa a esses movimentos a elaboração de um projeto totalizante, já que este não se revela na aparência imediata assumida pelas contradições com as quais estão lidando e enfrentando. É nesse cenário que questões urbanas e relativas ao cada vez mais reivindicado "direito à cidade" passam a ocupar papel relevante na pauta política dos movimentos sociais, com destaque para os 
movimentos que têm as ocupações de praças e espaços públicos como método e/ou o próprio conteúdo da política.

Justamente por isso, e percebendo que tal pauta é apropriada e reivindicada de diferentes formas e sob concepções, algumas vezes, inclusive contraditórias, consideramos relevante que, nessa primeira caracterização dos movimentos, nos atentemos mais detidamente a essa questão. Pensando as maneiras pelas quais as contradições do capitalismo em crise são vivenciadas por meio de uma série de aspectos da vida urbana, no centro e na periferia da economia mundial, buscaremos refletir sobre seus vínculos com a subjetividade, a cultura e as formas de organização política.

"A cidade tem sido por muito tempo um epicentro de criatividade destrutiva" (HARVEY, 2013, p. 31). A frase do geógrafo britânico Harvey (2013), um dos principais pensadores e críticos contemporâneos sobre a questão da cidade e da cultura no capitalismo, é um instigante ponto de partida para pensarmos as confluências entre a questão urbana, as expressões subjetivas/culturais e a política sob as condições do capitalismo contemporâneo e seu momento de crise. Partindo do conceito de trabalho em Marx (1988) e sua associação com a imaginação/abstração e a construção, Harvey (2013) destaca que somos todos arquitetos de nosso futuro urbano, feitores da cidade e, dialeticamente, sendo por ela feitos em circunstâncias que não escolhemos. Assim, a relação com a política é, também, uma relação com a cidade e suas formas no capitalismo atual.

Como muitos têm apontado (HARVEY, 2013, 2014; MARICATO, 1996, 2013), as cidades se tornam espaços privilegiados para a reciclagem de capitais, apoiados nas demandas de investimentos de longo prazo, como a construção de grandes estruturas (pela lógica da "produção destrutiva"), e na expansão imobiliária que, ao mesmo tempo, detona crises e as resolve pela perspectiva do capital

Consolida-se, assim, o processo em que a cidade se torna prioritariamente uma mercadoria e funciona sobretudo como um polo para atração de investimentos, e não um espaço para moradia e desenvolvimento das subjetividades dos indivíduos - o que, como se sabe, é acompanhado pela instauração de um mal-estar generalizado, marcado pela precariedade dos direitos elementares para a vida urbana. Transporte, para que se possa acessar e viver a cidade, saúde, moradia, lazer, educação, saneamento e outros direitos básicos são também eles mercantilizados e inseridos nos grandes balcões de negócios montados pelo empresariado e poder público. É esse contexto que, segundo Harvey 
(2013), coloca a questão urbana como epicentro das lutas políticas recentes em todo o mundo, que aparecem como cristalizações do mal-estar típico das cidades-mercadoria.

O geógrafo chama atenção para como, no caso das manifestações no Brasil e também na Turquia, em 2013, muito facilmente se partiu de algo pontual, específico e relacionado a uma demanda urbana, para processos de mobilização nacionais que, se obviamente guardavam relações com o estopim inicial, ao mesmo tempo ampliavam a pauta para as demandas mais sensíveis dos países. Ele aponta, assim, como o "direito à cidade" necessariamente emerge nesse contexto como uma pauta capaz de unificar movimentos sociais e as demandas populares por saúde, moradia, educação, passe-livre e, também, por democracia nas decisões políticas, mas, ao mesmo tempo, pode facilmente diluir-se em uma pauta genérica e incapaz de operar as necessárias sínteses para o enfrentamento aos interesses dominantes instituídos.

Harvey (apud NOGUEIRA, 2015, não paginado) alerta que se "todos gostam do direito à cidade", também as empreiteiras, os bilionários e políticos da ordem compõem essa gama de sujeitos. Segundo Harvey (2014), os setores dominantes podem, sem romper com a lógica da cidade-mercadoria, reivindicar o direito à sua cidade: aos negócios, às negociatas, à valorização de capitais, aos grandes eventos e à expansão da dinâmica mercantil do espetáculo para toda a sociabilidade urbana.

Assim, segundo o geógrafo, diante de um significante amplo e, possivelmente, vazio do "direito à cidade", parte fundamental da luta política atual está na batalha pelo seu sentido igualitarista e o seu potencial de enfrentamento à lógica mercantil instituída. Parece-nos importante sinalizar que também nessas formulações de Harvey (2014) há um grau de indeterminação que não dá suficientes respostas sobre o conteúdo da luta política no contexto urbano: afinal, o "sentido igualitarista" não seria, também ele, um significante amplo e passível de esvaziamento/apropriação? Em que medida ele se contrapõe, e de que formas objetivas, à lógica mercantil? E em quais termos isso se traduz nas lutas políticas?

A identificação dessa disputa política que ocorre, inclusive, em torno à pauta do "direito à cidade", nos ajuda a entender mais profundamente os termos das conexões entre a cidade, a política e a cultura, que aparece como campo fundamental tanto das pautas de reivindicação do direito à cidade em suas variadas formas como do próprio processo de valorização do capital nas cidades-mercadoria. A expansão da dinâmica do espetáculo, compreendido como uma relação social mediada por imagens, para a sociabilidade urbana 
está combinada aos interesses e à lógica mercantil, reforçando as dinâmicas eventivas e espetaculares que compõem o circuito das cidades-mercadoria.

Nesse contexto em que a cidade-mercadoria demanda e se associa à imagemmercadoria (dito de maneira mais ampla, à cultura) (EXISTE..., 2013), observamos a cultura mercantilizada passando a ter como um de seus produtos mais dinâmicos nos centros urbanos que explodem em contradições justamente um diluído "direito à cidade", nos termos pontuados por Harvey (2014, p. 20). Uma espécie de sobreposição entre um vago movimento social - o "protesto sem protesto" analisado por Viana (2013, p. 56) - e a realização de eventos culturais nos espaços públicos - em que a utilização dos espaços e equipamentos urbanos passa a ser a própria pauta - ganha, assim, destaque apoiando-se em um turvo referencial de contraposição à lógica privatista e excludente das cidades e no "fazer coletivo", sem que isso se traduza objetivamente em uma pauta política. Mais do que isso, a cultura mercantilizada encontra aí um importante e renovado filão que, na lógica do capital, associa-se aos interesses de imobiliárias, empreiteiras e demais segmentos "clássicos" da economia capitalista.

Observamos, assim, a detonação de transformações também na esfera ideológica e na produção do consenso, que passa a incorporar e valorizar de maneira destacada algumas das iniciativas vinculadas a essa diluída reivindicação do "direito à cidade". Insatisfação, mal-estar urbano, vontade de mudança e uma juventude disposta a engajarse em diversas formas de produção cultural e debate político são elementos concretos das experiências cotidianas que, sem dúvida, carregam um potencial crítico e antissistêmico, revelador das estruturas sociais e dos interesses em disputa no contexto urbano. O que nos parece interessante sublinhar diante das reflexões apresentadas é o fato de esse potencial não representar uma pauta "resolvida" e suficiente, mas, pelo contrário, mais um elemento da disputa política atual. Na imbricação da cidade-mercadoria com a cultura-espetáculo, os anseios por mudanças têm sido captados.

É fundamental pensar as formas pelas quais as experiências com as contradições na e da cidade são percebidas e elaboradas na consciência, contribuindo para o entendimento dos caminhos de sua apropriação pelo consenso estabelecido. Pensar, assim, as formas de aprofundamento da reificação na cultura contemporânea é um passo fundamental diante de um quadro em que as contradições objetivas são percebidas de maneira fragmentada, serializada e no sentido oposto da elaboração de uma perspectiva totalizante. 
Nesse sentido, nos ajudam as reflexões propostas por Iasi (2013) em A rebelião, a cidade e a consciência. Para entender de que forma os processos de formação da consciência, atravessados pela ideologia e pela reificação, desenvolvem-se no contexto urbano e suas especificidades, o intelectual parte do entendimento de que a própria cidade, em si, é a forma reificada das relações sociais de produção capitalistas e, ao mesmo tempo, o amadurecimento das contradições que estas carregam e engendram. A cidade, assim, não é vista abstratamente como um “espaço", mas sim como uma expressão dessas relações sociais de produção que, por sua vez, não é assim percebida pela consciência/subjetividade dos indivíduos nela inseridos (IASI, 2013, p. 73). Na consciência, os indivíduos vivem a explosão das contradições urbanas como serialidades compartimentadas, indicando exatamente como a reificação estrutura a leitura da vida social. Segundo Iasi (2013, p. 76), a consciência assume a forma particular da realidade social como "a realidade em si", operando por movimentos de particularismo, superficialidade extensiva e ultrageneralização.

Pensando a ideologia em sua acepção "clássica", como as relações sociais de produção concebidas como ideias, Iasi (2013) destaca seu papel em operar uma soldagem da objetividade e suas contradições em uma subjetividade marcada pela adequação permanente ao real, dando sentido à subordinação e ao mal-estar urbano, se quisermos usar o termo de Harvey (2013) descrito acima. A ideologia e a reificação, assim, são dimensões essenciais da formação da consciência diante das contradições urbanas e, como tal, operam na subjetividade e na esfera da cultura, notadamente na comunicação. Os produtos culturais, ofertados em abundância, reforçam a lógica mercantil e operam a "soldagem da subjetividade" que obstaculiza os movimentos totalizantes na consciência.

Nesse cenário, a própria comunicação, como tal, é percebida de maneira reificada. A fragmentação na compreensão do existente leva a uma percepção do papel (cada vez mais decisivo) da comunicação de maneira descolada das dinâmicas que a envolvem. As próprias questões referentes às dificuldades para a mobilização social dos grupos subalternos e os obstáculos à organização das formas de resistência, indubitavelmente associadas à formação da consciência e, assim, à ideologia e a reificação, passam a ser percebidas como meras "falhas na comunicação", como destaca Iasi (2013).

\section{A comunicação que não questiona o seu próprio referente material está fadada à reprodução da lógica do mercado simbólico}


É fundamental entendermos os mecanismos pelos quais o capitalismo contemporâneo potencializa o papel material e ideológico desempenhado pelos meios de comunicação e recoloca, assim, as questões da comunicação e da cultura na formação da consciência e na sociabilidade contemporânea, como temos apontado neste artigo.

Jameson (1996) nos ajuda nesse esforço, em O pós-modernismo e o mercado, e destaca as modificações profundas da esfera pública com o aparecimento de "um novo domínio da realidade das imagens" que é simultaneamente ficcional (narrativo) e factual (à medida que as narrativas adquirem concretude na vida material). Isso aponta, segundo Jameson (1996), para a tendência de semiautonomização da esfera da cultura, que se converte em algo que parece pairar acima da realidade concreta, com a diferença de que, no período clássico, a realidade material persistia independentemente da esfera cultural. Hoje, a realidade material parece perder sua modalidade de existência em separado. A imbricação permanente entre estrutura e cultura aponta para um momento em que a cultura tem tanto impacto na realidade "que torna problemática qualquer forma de realidade não cultural ou extracultural” (JAMESON, 1996, p. 283), levando às interpretações correntes de que o referente concreto deixa de existir.

É nesse cenário, portanto, que a mediação das imagens e produtos culturais passa a exercer centralidade. A crítica ao capitalismo contemporâneo e o seu enfrentamento, ao incorporar o lugar da comunicação e da cultura, não precisam fazê-lo ignorando as mediações estruturais e aceitando acriticamente a aparência (mercantil) de autonomização do simbólico. Pelo contrário, essa crítica deve ser parte constitutiva do projeto totalizante para enfrentar essa ordem. Afinal, aproximando essas considerações de Jameson (1996) com a análise das determinações econômicas do capitalismo contemporâneo, parece-nos clara a relação entre a predominância da lógica do capital fictício no padrão de acumulação capitalista com um período marcado pela lógica de autonomização do simbólico e falta de referência nas determinações estruturais e produtivas da atual forma de sociabilidade. O descarte dos vínculos materiais e dinâmicas produtivas ganha espaço num período em que o capital se submete a uma lógica que tende, justamente, a apontar a autonomização de sua reprodutibilidade em relação à esfera produtiva.

A cultura, assim, passa a assumir um lugar de "fato em si", que se inicia e encerra nas suas próprias dinâmicas, apoiada nas transformações técnicas que permitem uma difusão sem precedentes de seu conteúdo, que se expande para todo tecido da vida social. 
Não há um lugar "de fora" da cultura dominante; esta, ao negar seu referente material, traz implícita e impregnada em suas formas a lógica mercantil que a constitui.

O tema da comunicação nos ajuda a refletir sobre as condições materiais das lutas políticas no capitalismo contemporâneo, a entender o papel da produção simbólica na formação da consciência e nas mediações desenvolvidas pelos indivíduos, assim como os motivos e consequências do papel de destaque ocupado pela comunicação e pela cultura.

Ajudam-nos nessa reflexão as formulações de Paulo Netto (2011) em seu posfácio à reedição de $O$ estruturalismo e a miséria da razão, de Coutinho (2011). Paulo Netto (2011) reafirma a necessidade de compreensão do capitalismo contemporâneo em suas especificidades, como uma forma de sociabilidade que rege o mundo e apresenta fenômenos novos, exigindo, assim, instrumentos analíticos capazes de corresponder às novidades colocadas. Não se trata, assim, de desconhecer as transformações pelas quais passou o capitalismo desde os anos 1970 e, consequentemente, de ignorar a necessidade de recursos teóricos capazes de abarcar tais transformações:

Ele [o capitalismo] não pode ser tratado teoricamente tal como o foi até os anos 1970: novos problemas, novas questões e novas alternativas se põem na sua realidade [...]. Mas é necessário insistir enfaticamente em que ele é e continua sendo capitalismo - um modo de produzir/reproduzir relações sociais a partir da produção material das condições de vida social, produção fundada na exploração do trabalho, contendo contradições e limites imanentes à sua estrutura e dinâmica (de que a mais recente prova, e não certamente a última, foi a crise aberta pelo crash financeiro de 2008) (PAULO NETTO, 2011, p. 258, grifo nosso).

A identificação, assim, das transformações características do capitalismo contemporâneo não deve induzir à negação de sua caracterização como sistema capitalista, nem ao abandono das categorias centrais que cabem para sua análise e transformação. Classes sociais, exploração do trabalho e ruptura revolucionária são, assim, temas pertinentes e indissociáveis da realidade contemporânea, como buscamos demonstrar.

É nesse sentido que nossa análise procura se contrapor às formulações associadas às teorias pós-modernas que, como discutimos, encaram a sociedade contemporânea como a expressão da superação definitiva dessas mesmas questões. Essas formulações, como também enfatizamos, reafirmam a centralidade da cultura nas manifestações políticas como suposta comprovação da imaterialidade e autonomia permanente do simbólico na sociedade contemporânea e defendem a descentralização, a difusão e a fragmentação política como inexoráveis na contemporaneidade. 
Aqui, incorporaremos a crítica de Paulo Netto (2011, p. 261) ao que identifica como o "denominador comum" das teorias pós-modernas, para defender a categoria da totalidade e seu lugar indispensável no debate que estamos travando. Acreditamos que a identificação desses traços, considerados por Paulo Netto (2011) como linhas fundamentais e comuns a essas formulações, ajuda-nos a entender seus limites e como se expressam especificamente no tratamento dos movimentos sociais contemporâneos. São eles: (a) a aceitação da imediaticidade com que se apresentam os fenômenos socioculturais como expressão de sua inteira existência e de seu modo de ser, o que suprime a distinção clássica entre aparência e essência; (b) a recusa da categoria de totalidade, tida como algo anacrônico diante das transformações societárias contemporâneas; e (c) a semiologização da realidade social, com o privilégio concedido às dimensões simbólicas na vida social que termina por reduzi-la à discursividade ou ao domínio do signo.

Como dissemos, esses três elementos aparecem de maneira definitiva nas análises sobre os movimentos sociais contemporâneos às quais buscamos apresentar uma contraposição. Afinal, a aparência imediata e fragmentada dos movimentos sociais, como fenômenos socioculturais, não é tomada a partir da mediação entre aparência e essência, mas sim como uma suposta confirmação da inexorabilidade dessa fragmentação e difusão. Esse pressuposto se relaciona com uma recusa da categoria de totalidade em defesa de uma suposta desarticulação intransponível e típica da contemporaneidade, combinada justamente às produções simbólicas que se autonomizam e deixam de ser analisadas em suas relações com a vida social material.

Para questionarmos esses pressupostos e avançarmos no sentido da formulação de uma compreensão que recoloque a categoria da totalidade, retomamos, necessariamente, Lukács (2003), em O que é o marxismo ortodoxo, que nos demonstra a diferença entre a existência real dos fatos e seu núcleo interior:

Trata-se, de uma parte, de arrancar os fenômenos de sua forma imediatamente dada, de encontrar as mediações pelas quais eles podem ser relacionados ao seu núcleo e sua essência e tomados em sua essência mesma, e, doutra parte, de alcançar a compreensão deste caráter fenomênico, desta aparência fenomênica, considerada como sua forma de aparição necessária. Esta forma de aparição é necessária em razão de sua essência histórica, em razão de sua gênese no interior da sociedade capitalista (LUKÁCS, 2003, p.75, grifo nosso).

Como destaca Lukács (2003, p. 76, grifo do autor), “[...] é somente nesse contexto, que integra os diferentes fatos da vida social numa totalidade, que o conhecimento dos 
fatos torna-se possível como conhecimento da realidade". Acreditamos, assim, que essas são formulações que nos ajudam a superar a constatação acrítica da imediaticidade aparente dos movimentos sociais contemporâneos como sua expressão definitiva e essencial. Da mesma forma, contribuem para entender que essa expressão imediata e aparente é parte necessária de um par dialético entre aparência e essência e precisa ser levada em conta como tal, pois revela as condições de aparição do fenômeno no interior da sociedade capitalista.

\section{Referências}

CARCANHOLO, Marcelo. Conteúdo e forma da crise atual do capitalismo: lógica, contradições e possibilidades. Crítica e Sociedade, v. 1, n. 3, dez. 2011.

CASTELLS, Manuel. Redes de indignação e esperança: movimentos sociais na era da internet. Rio de Janeiro: Zahar, 2013.

COUTINHO, Carlos Nelson. O estruturalismo e a miséria da razão. São Paulo: Expressão Popular, 2011.

EXISTE consenso em SP? Reflexões sobre a questão da cultura. Passa Palavra, 18 fev. 2013. Disponível em: http://passapalavra.info/2013/02/72682. Acesso em: 17 maio 2017.

HARVEY, David.A liberdade da cidade. In: MARICATO, Erminia et al. Cidades rebeldes: passe livre e as manifestações que tomaram as ruas do Brasil. São Paulo: Boitempo: Carta Maior, 2013. p. 47-61.

HARVEY, David. Cidades rebeldes: do direito à cidade à revolução urbana. São Paulo: Martins Fontes, 2014.

IASI, Mauro. A rebelião, a cidade e a consciência. In: MARICATO, Erminia et al. Cidades rebeldes: passe livre e as manifestações que tomaram as ruas do Brasil. São Paulo: Boitempo: Carta Maior, 2013. p. 73-84.

JAMESON, Fredric. Pós-modernismo: a lógica cultural do capitalismo tardio. São Paulo: Ática, 2002.

JAMESON, Fredric. O pós-modernismo e o mercado. In: ZIZEK, Slavoj. Um mapa da ideologia. Rio de Janeiro: Contraponto, 1996, p. 279-296.

JINKINGS, Ivana (org). Occupy: movimentos de protesto que tomaram as ruas. São Paulo: Boitempo, 2012.

LUKÁCS, Gyorgy. O que é o marxismo ortodoxo? In: Reificação e consciência de classe: História e consciência de classe. São Paulo: Martins Fontes, 2003, p. 63-104.

MARICATO, Ermínia et al. Cidades rebeldes: passe livre e as manifestações que tomaram as ruas do Brasil. São Paulo: Boitempo: Carta Maior, 2013. 
MARICATO, Ermínia. Metrópole na periferia do capitalismo: ilegalidade, desigualdade e violência. São Paulo: Hucitec, 1996.

MARX, Karl. O capital. Rio de Janeiro: Bertrand Brasil, 1988.

NOGUEIRA, Pedro Ribeiro. David Harvey: "Nós estamos construindo cidades para investir, não para viver". Portal Aprendiz, 10 jun. 2015.

Disponível em: https://portal.aprendiz.uol.com.br/2015/06/10/david-harvey-nosestamos-construindo-cidades-para-investir-nao-para-viver/. Acesso em: 3 jan. 2020.

PAULO NETTO, José. Posfácio. In: COUTINHO, Carlos Nelson. O estruturalismo e a miséria da razão. São Paulo: Expressão Popular, 2011. p. 233-285.

TOUSANDS of protesters occupy Puerta del Sol square in Madrid. The Telegraph, [S.d.]. Disponível em:

https://www.telegraph.co.uk/news/picturegalleries/worldnews/8525938/Thousands-ofprotesters-occupy-Puerta-del-Sol-square-in-Madrid.html?image=1. Acesso: 3 jan. 2020.

VIANA, Silvia. Será que formulamos mal a pergunta? In: MARICATO, Erminia et al. Cidades rebeldes: passe livre e as manifestações que tomaram as ruas do Brasil. São Paulo: Boitempo: Carta Maior, 2013. p. 95-105.

Submetido em: 09/10/2019

Aprovado em: 30/10/2019 